\title{
Combining Terapixel-Scale SEM Imaging and High-Resolution TEM Studies for Mineral Exploration.
}

Dirk Schumann ${ }^{1,2}$, Sebastian Fuchs ${ }^{3}$, Jessica Stromberg ${ }^{2}$, Alexandre Laquerre ${ }^{1}$, David Mayer ${ }^{1}$, Michael W Phaneuf ${ }^{1}$, Hojatollah Vali ${ }^{4}$ and Neil Banerjee ${ }^{2}$.

1. Fibics Incorporated, Ottawa, Canada.

2. Department of Earth Sciences, Western University, London, Canada

${ }^{3}$ Department of Earth and Planetary Sciences, McGill University, Montreal, Canada

${ }^{4}$ Facility for Electron Microscopy Research, McGill University, Montreal, Canada

Mineral exploration can be an exceedingly expensive endeavor for mining companies. Any tool that routinely increases exploration or extraction efficiencies has the potential to create economic returns of millions of dollars. The in situ characterization of minerals associated with ore zones and geochemical anomalies has the potential to be such a tool. Recent advancements in transmission-electron microscopy (TEM) sample preparation techniques using the latest generation focused-ion beam and scanningelectron microscope (FIB-SEM) instrumentation allows for high-resolution examination of textures, elemental composition and structures of minerals at unprecedented resolution [1] [2]. These techniques, however, have been rarely applied to ore deposits [3]. For example, the knowledge of how gold occurs within sulphide minerals (e.g., in the lattice of the host mineral or as nanoparticles) is of great importance to mineral exploration and mining companies in order to define effective exploration and extraction methods. Bulk rock and microprobe analyses alone lack the spatial resolution and sensitivity necessary to accomplish the required level of characterization.

Here we present a suite of advanced SEM, FIB and TEM techniques that can be applied sequentially and quickly. Two samples from the Timmins-Porcupine gold camp (Canada) and the Witwatersrand gold/uranium deposit (South Africa) were analyzed using high-resolution large area SEM imaging, microprobe analyses, TEM specimen preparation in the FIB microscope, and subsequent high-resolution TEM (HRTEM) characterization.

The gold hosting mineral in the Timmins-Porcupine gold deposit is primarily pyrite that contains free gold as inclusions, as fracture filling and along grain boundaries as well as "invisible" gold in arseno pyrite. The gold in the Witwatersrand sample is associated both with pyrite and uraninite that occur in conglomerate horizons that contain solidified bitumen.

The samples were first imaged in a Carl Zeiss Sigma HD field emission SEM using the "Atlas" highresolution large area imaging tool, which provides a comprehensive, fast, and user friendly means to define, execute and observe images on a SEM system at up to one gigapixel in size per image, and to acquire and manipulate multi-image mosaics of large areas. Entire petrographic thin sections were imaged in the SEM-BSE mode at resolutions of 200 and $50 \mathrm{~nm} /$ pixel (Fig. 1a, g). Selected areas that contained gold and arseno pyrite mineralizations were additionally scanned at 10 and $15 \mathrm{~nm} / \mathrm{pixel}$ (Fig. $1 \mathrm{~b}, \mathrm{c}, \mathrm{h}, \mathrm{i})$. The acquired image mosaics were combined with microprobe elemental maps and regions of interest for FIB foil extraction were identified. 
The HRTEM analyses on the FIB foils from the Witwatersrand sample revealed a new result: that the uraninite and gold crystallization occured (at different stages) during liquid oil and water intermixing (Fig. 1d, e, f). The sequence of techniques applied in this study enabled quick and systematic in situ characterization of gold mineralization from the millimeter to the nanometer scale [4].

\section{References:}

[1] R Wirth, European Journal of Mineralogy 16 (2004), p. 863.

[2] R Wirth, Chemical Geology 261 (2009), p. 217.

[3] CL Ciobanu, NJ Cook, S Utsunomiya, A Pring, and L Green, Ore Geology Reviews 42 (2011), p. 6. [4] AngloGold Ashanti Ltd. and Goldcorp Porcupine Gold Mines are thanked for providing the samples.
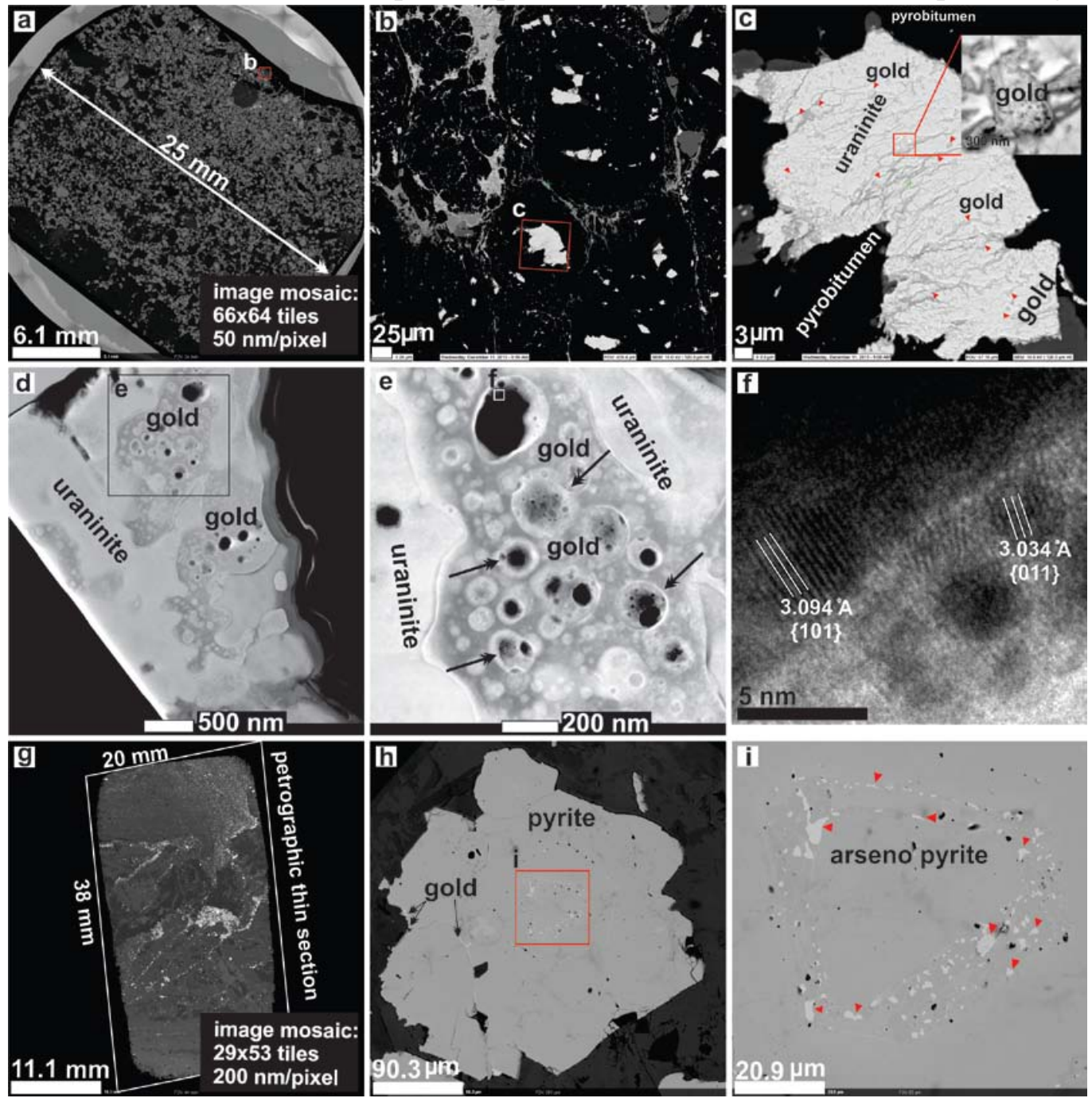

Figure 1. (a) SEM-BSD image mosaic of the Witwatersrand sample; (b) bitumen with uraninite aggregates; (c) uraninite aggregate with gold in the pore spaces, (d) HAADF TEM image of FIB foil from a similar uraninite aggregate as shown in (c), (e) HAADF TEM image of outlined area in (d). Pore spaces in uraninite aggregates are filled with gold that shows inclusions of solid bitumen (black arrows), (f) Bright field TEM lattice-fringe image of uraninite nanocrystals within solid bitumen inclusions, (g) SEM-BSD mosaic of the Timmins-Porcupine gold deposit sample, (h) gold (black arrows) hosting pyrite grain, (i) zone of arseno pyrite inclusions in the pyrite grain of (h). 